\section{Research Square}

Preprints are preliminary reports that have not undergone peer review.

They should not be considered conclusive, used to inform clinical practice, or referenced by the media as validated information.

\title{
Female Students Use More Language Learning Strategies Than Male Students? - A Case Study of ESL Learners in a Macau Public University
}

Don Yao ( $\sim$ yb87710@um.edu.mo)

University of Macau

Original article

Keywords:

Posted Date: November 13th, 2020

DOl: https://doi.org/10.21203/rs.3.rs-106415/v1

License: (c) (1) This work is licensed under a Creative Commons Attribution 4.0 International License. Read Full License 


\section{Abstract}

Language Learning Strategies (LLSs) as a pluralistic and pervasive strategic system (Yan \& Zha, 2011, p. 1) always attaches great importance of Second Language Acquisition (SLA). Numerous researchers have been working on this topic since the 1970s. Also, since students differ from person to person in their adoption of learning strategies and the research on differences in individuals develops, the topic of gender differentiation has arisen in the LLSs. Research related to gender and LLSs has been brought to the forefront in the last three decades, and many studies have found that gender can have a significant impact on LLSs (Zafar, 2012, p. 640). In China, most of the previous studies in learning strategies have paid attention to age, motivation, aptitude, educational level, good language learners, etc. But not much has been done in terms of the perspective of gender. Also, as one of the special economic zones in China, researchers may neglect the importance of Macau for most of them have focused more on Hong Kong. This paper then investigated the use of LLSs by a group of ESL learners in a Macau public university. It emphasized the gender differences and aimed to find out how gender affected the use of LLSs. Quantitative research method was adopted in this paper. A total of $188 \mathrm{ESL}$ learners $(M=92, F=96)$ participated in this study. The instrument Oxford's 50 -item Strategy Inventory for Language Learning (SILL) questionnaire was used. In consideration of their English proficiency levels, Liao's (2002) Chinese version of the SILL questionnaire was adopted so that it was easier for students to understand. Moreover, the statistical software SPSS 22.0 was used for statistical analysis. The major findings were that gender as a variable affected students' strategy use with female students (

$X=3.26) m$ or eequentlyusedstrategiesthanma $\leq$ students $(\mathrm{X}=3.22)$, and they both used metacognitive strategies the most $(\mathrm{M}: X=3.41 ; F: \mathrm{X}=$ 3.49) and memory strategies the least ( $\mathrm{M}: X=3.01 ; F: \mathrm{X}=3.11)$. In terms of gender and frequency of LLSs use, metacognitive strategies showed the strongest correlation $(r=.88)$ and memory strategies showed the weakest $(r=.64)$. To sum up, for students, they can learn English more efficiently and effectively with the guidance of proper learning strategies. And students with gender differentiation will use more useful strategies when learning a foreign language; For teachers, they can teach students with their actual needs with the help of learning strategies.

\section{Introduction}

With the development of economic globalization and international cooperation, more and more Chinese people have realized the significance of learning a second language, especially English. Language Learning Strategies (LLSs) as a pluralistic and pervasive strategic system (Yan \& Zha, 2011, p. 1) always attaches great importance of Second Language Acquisition (SLA).

Before the 1960s, behaviouristic psychology which played a dominant role stressed the "stimulus" and "response" separately but ignored the relationship between them. Thus, the drawback of behaviouristic psychology was extremely obvious. Also, the theoretical foundation was based on experiments mainly with animals rather than human beings. One could imagine that the result may not totally be appropriate for human beings. In the 1960 s, influenced by cognitive psychology, researchers began to realize that cognitive activity was a complex process of both "thinking" and "problem solving." Language learners were not only passive stimulated persons or responders but also positive thinkers and problem solvers. Therefore, cognitive psychology offered a new theoretical basis for the research on LLSs. From the 1970s to now, numerous researchers have been working on this topic. However, since students differ from person to person in their adoption of learning strategies, and the research on individuals develops, the topic of gender differentiation has arisen in the LLSs. In the last three decades, research related to gender and LLSs have found that gender can have a significant impact on LLSs (Zafar, 2012, p. 640).

In China, previous studies in learning strategies have mostly paid attention to age, motivation, aptitude, educational level, good language learners, etc. But not much has been done in terms of gender and LLSs. Also, as one of the special economic zones in China, researchers may neglect the importance of Macau for most of them have focused more on Hong Kong. I strongly argue that it is essential to carry out this study. For students, they can learn English more efficiently and effectively with the guidance of proper learning strategies. And students with gender differentiation will use more useful strategies when learning a foreign language; For teachers, they can teach students with their actual needs with the help of learning strategies.

This paper is a part of an ongoing investigation that aims to find out how gender affects the use of LLSs among 188 students in a Macau public university learning English as a second language. The instrument Oxford's 50-item Strategy Inventory for Language Learning (SILL) questionnaire was used this time. And SPSS 22.0 was used for statistical analysis.

\section{Literature Review}

\section{Definitions of Language Learning Strategies (LLSs)}

LLSs are especially important for language learning because they are tools for active, self-directed involvement, which is essential for developing communicative competence (Zhang, 2012, p.5). The concept of LLSs has been defined by many researchers (Stern, 1983; Weinstein \& Mayer, 1986; Chamot, 1987; Rubin, 1987; Oxford, 1989). Rod Ellis (1994) offered the following definitions of LLSs put forward by well-known linguists.

\section{Table 1}

Definitions of LLSs (in the 1980s)

Source Definition



techniques as the term to refer to particular forms of observable learning behaviour."

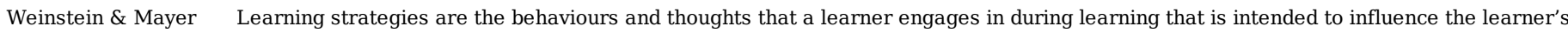

(1986) encoding process."

Chamot (1987)

"Learning Strategies are techniques, approaches or deliberate actions that students take in order to facilitate the learning, recall of both linguistic and content area information."

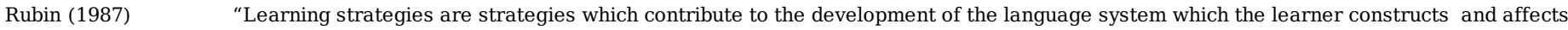
learning directly."

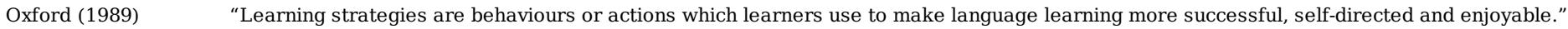

From the definitions above, it is hard to say whether LLSs belong to behaviours or consciousness, or both. Not until the 1990 s did researchers begin to realize that learning strategy is a comprehensible but not an observable language learning method

\section{Table 2}

Definitions of LLSs (from the 1990s to now)

\begin{tabular}{|c|c|}
\hline Source & Definition \\
\hline $\begin{array}{l}\text { O’Malley \& } \\
\text { Chamot } \\
\text { (1990) }\end{array}$ & $\begin{array}{l}\text { “Learning strategies are special thoughts or behaviours that individuals use to help them comprehend, learn or retain new information." (O' Malley \& } \\
\text { Chamot, 1990, p.21) }\end{array}$ \\
\hline $\begin{array}{l}\text { Cohen } \\
(1990)\end{array}$ & “Learning strategies are learning processes which are consciously selected by the learner.” (Cohen, 1990, p. 279) \\
\hline $\begin{array}{l}\text { Oxford } \\
(1992)\end{array}$ & $\begin{array}{l}\text { "Learning strategies are behaviours or actions which learners use to make language learning more successful, self-directed and enjoyable. These } \\
\text { strategies can facilitate the internalization, storage, retrieval, or use of the new language. Strategies are tools for self-directed involvement necessary } \\
\text { for developing the communicative ability." (Oxford, 1992, p.235) }\end{array}$ \\
\hline $\begin{array}{l}\text { Nunan } \\
(1999)\end{array}$ & “Learning strategies are mental and communicative procedures learners use during learning in order to learn and use language.” (Nunan, 1999, p.123) \\
\hline $\begin{array}{l}\text { Richard } \\
\text { \&Platt } \\
(2000)\end{array}$ & $\begin{array}{l}\text { "Learning strategies are international behavior and thoughts that learners make use of during learning in order to better help them understand, learn or } \\
\text { remember new information." (Richard \& Platt, 2000, p.165) }\end{array}$ \\
\hline
\end{tabular}

The most well-known definition was provided by Oxford (1990). She claimed that LLSs have the following features: 1. Contribute to the main goal, communicative competence; 2 . Allow learners to become more self-directed; 3 . Expand the role of teachers; 4 . Are problem-oriented; 5 . Are specific actions taken by the learner; 6 . Involve many aspects of the learner, not just the cognitive; 7 . Support learning both directly and indirectly; 8 .Are not always observable; 9. Are often conscious; 10. Can be taught; 11. Are flexible; 12. Are influenced by a variety of factors (Oxford, 1990, p.9). Oxford's (1990) definition considered existing research findings and made them more specific. She also reclassified LLSs and explained each of them in detail.

\section{Classifications of LLSs}

With the development of strategy research, classifying LLSs has been a vital concern for researchers. Then, four of the most well-known frameworks were put forward by O'Malley \& Chamot (1990), Oxford (1990), Cohen (1998) and Wen (1995).

\section{O'Malley and Chamot's Classification}

O'Malley and Chamot are pioneers in classifying LLSs. Based on Anderson's (1983) cognitive theory and information processing theory, they divided LLSs into cognitive strategies, metacognitive strategies and social and affective strategies. In their opinion, metacognitive strategies are higher order executive skills that may entail planning for, monitoring or evaluating the success of a learning activity (Bransford, Brown, Ferrara \& Campione, 1983). Cognitive strategies operate directly on incoming information, manipulating it in ways that enhance learning. And it may be limited in application to the specific type of task in the learning activity. Social and affective strategies represent a broad grouping that involves either interaction with another person or ideational control over effect (O’Malley \& Chamot, 1990, p. 44-45).

\section{Table 3}

O'Malley and Chamot's Classification of LLSs (O'Malley \& Chamot, 1990)

Researcher (s) Classification of LLSs




\begin{tabular}{|c|c|c|}
\hline & Cognitive strategies & "Resourcing, keyword method, inferencing, note- taking, recombination, translation." \\
\hline O’Malley \& & Metacognitive strategies & “Advance organizers, directed attention, functional planning, selective attention, self-management, self-monitoring \\
\hline Chamot (1990) & & and self-evaluation.” \\
\hline
\end{tabular}

Social and affective strategies "Cooperation, question for clarification."

(O’Malley \& Chamot, 1990, p.1)

Although O'Malley and Chamot offered a classification that laid emphasis on metacognitive and cognitive strategies, they ignored the role of social and affective strategies in language learning. Therefore, this classification may not be comprehensive enough.

\section{Oxford's Classification}

Oxford summarized other researchers' findings and refined them. Then, she divided LLSs into six categories, three of which belonged to direct strategies and the other three belonged to indirect strategies. Memory strategies, cognitive strategies and compensatory strategies are direct strategies, while metacognitive strategies, affective strategies and social strategies are indirect strategies.

From her point of view, for direct strategies, memory strategies are about creating mental linkages, applying images and sounds, reviewing well and employing action. Cognitive strategies are essential in practicing, receiving and sending messages, analyzing and reasoning and creating a structure for input and output. Compensatory strategies are about guessing intelligently and overcoming limitations in speaking and writing (Oxford, 1990, p.38). For indirect strategies, metacognitive strategies aim at centering one's learning, arranging and planning one's learning and evaluating one's learning. Affective strategies are contributed to lowering one's anxiety, encouraging oneself and taking one's emotional temperature. Social strategies are about asking questions, cooperating with others and empathizing with others (Oxford, 1990, p.136)

\section{Table 4}

Oxford's Classification of LLSs (Oxford, 1990)

Researcher (s) Classification of LLSs

\begin{tabular}{|c|c|c|c|}
\hline & & $\begin{array}{l}\text { Memory } \\
\text { strategies }\end{array}$ & "Creating mental linkages, applying images and sounds, reviewing well and employing action." \\
\hline & $\begin{array}{l}\text { Direct } \\
\text { strategies }\end{array}$ & $\begin{array}{l}\text { Cognitive } \\
\text { strategies }\end{array}$ & $\begin{array}{l}\text { "Practicing, receiving and sending messages, analyzing, reasoning and creating a structure for input and } \\
\text { output." }\end{array}$ \\
\hline \multirow[t]{4}{*}{ Oxford (1990) } & & $\begin{array}{l}\text { Compensatory } \\
\text { strategies }\end{array}$ & "Guessing intelligently and overcoming limitations in speaking and writing." \\
\hline & & $\begin{array}{l}\text { Metacognitive } \\
\text { strategies }\end{array}$ & “Centering one's learning, arranging and planning one's learning and evaluating one's learning." \\
\hline & $\begin{array}{l}\text { Indirect } \\
\text { strategies }\end{array}$ & $\begin{array}{l}\text { Affective } \\
\text { strategies }\end{array}$ & "Lowering one's anxiety, encouraging oneself and taking one's emotional temperature. \\
\hline & & $\begin{array}{l}\text { Social } \\
\text { strategies }\end{array}$ & "Asking questions, cooperating with others and empathizing with others." \\
\hline
\end{tabular}

(Oxford, 1990, p.245-247)

Oxford's classification is regarded as the most understandable and acceptable one. Ellis (1999) also stated that perhaps the most comprehensive classification of learning strategies to date was that provided by Oxford. Meanwhile, Oxford's questionnaire Strategy Inventory for Language Learning (SILL) was also widely adopted in later research.

\section{Cohen's Classification}

Cohen pointed out the importance of LLSs and Language Using Strategies (LUSs). He thought that LLSs are about identifying the material for learning, distinguishing it from other material, grouping it for easier learning, repeatedly engaging oneself in contact with the material, remembering it with efforts. And LUSs are about retrieval, rehearsal, cover and communication strategies.

\section{Table 5}

\section{Cohen's Classification (Cohen, 1990)}

Researcher (s) Classification of LLSs

LLSs "Identifying the material for learning, distinguishing it from other material, grouping it for easier learning, repeatedly engaging oneself in contact with the material, remembering it with efforts."

Cohen (1990)

"Retrieval strategies, rehearsal strategies, cover strategies and communication strategies."


Cohen's classification is very clear, but it is difficult for us to distinguish whether the activity belonged to LLSs or LUSs. Also, he ignored metacognitive strategies put forward by former researchers.

\section{Wen's Classification}

Wen not only stressed the relationship between learning strategies and learning process but also paid attention to the relationship between learning strategies and learning materials. Therefore, she divided learning strategies into management strategies and LLSs. The former concept consists of cognitive process and affective process, while the latter one is composed of traditional LLSs and non-traditional LLSs.

In management strategies, managing cognitive process aims at setting a goal, making a plan, selecting strategies, self-monitoring and self-evaluation. Managing affective process is related to self-management. In the LLSs, traditional LLSs are related to form-focused, accuracy and mother-tongue-using strategies. Non-traditional LLSs are about meaning-focused, fluency and mother-tongue-avoidance strategies.

\section{Table 6}

Wen's Classification (Wen, 1995)

\begin{tabular}{|c|c|c|c|}
\hline Researcher (s) & Classification of LLSs & & \\
\hline & $\begin{array}{l}\text { Management } \\
\text { strategies }\end{array}$ & Cognitive process & $\begin{array}{l}\text { "Setting a goal, making a plan, selecting strategies, self-monitoring, and self- } \\
\text { evaluation." }\end{array}$ \\
\hline \multirow[t]{2}{*}{ Wen (1995) } & & Affective process & "Self-management" \\
\hline & & Non-traditional LLSs & $\begin{array}{l}\text { "Meaning-focused strategies, fluency strategies and mother-tongue-avoidance } \\
\text { strategies." }\end{array}$ \\
\hline
\end{tabular}

(Wen, 1995, p.159)

Wen's classification is very concise, but somewhat over general as well. It is difficult to classify some of learning strategies, e.g., communication strategies. All in all, Oxford's classification may be the most comprehensive one and it is also easy for others to understand. Her SILL questionnaire is also an excellent tool for researchers to use to find out what LLSs people tend to use. Therefore, in this paper, Oxford's framework was adopted for the further research.

\section{Research on Gender Differences in LLSs Outside China}

The past four decades have seen an upsurge of interest in LLSs. Many researchers have begun to realize the significance of LLSs. Of course, gender as an indispensable variable plays an important role in LLSs as well. In the recent two decades, research on LLSs has been more and more comprehensive. Since this paper examined the relationship between gender and LLSs, related studies were discussed in a chronological way.

\section{Research in the 1970s}

Research on LLSs started from the 1970s, with researchers examining English as an L2 as the object of study to do their research. Among the originators are Rubin (1975), Naiman et al. (1978), Wong-Fillmore (1976), Stern (1983) and so on.

Rubin (1975) is regarded as one of the most influential researchers for she carefully observed learning behaviours of "good language learners" and designed questionnaires and interviews to investigate their LLSs. In 1975, her classic What the "Good Language Learner" Can Teach us was published in TESOL Quarterly. She found that good language learners were accurate guessers. They could get and store important information in a quick way; good language learners had very strong ability to interact with others; good language learners were not inhibited. They were not afraid of making mistakes for they could learn something from those mistakes; good language learners often practiced. They laid emphasis on both word pronunciation practicing and sentences making up; and good language learners paid much attention to their performance. They focused on whether they met the standards when they talked to others, etc.

After Rubin, Naiman (1978) and others made some further step in LLSs. In 1978, they wrote the classic The Good Language Learner (Naiman et al., 1978, 1996). Compared with previous research, their research had huger improvements from breath, depth and research method. They found that good language learners found and made fully advantage of helpful academic environment to take part in language learning; good language learners formed the awareness that language is a formal system; good language learners took language as a medium to communicate and interact with others; good language learners positively accepted and handled affective needs when learning a foreign language; and good language learners expanded and amended their foreign language system by deducing and monitoring, etc. Wong-Fillmore's (1976) research was also indispensable for she took five Mexican children learning English in America as participants and investigated how these children improved their English communicative competence. She found that LLSs played an important role during their learning process.

These findings all laid a solid foundation for later research. However, whether gender played an important role in language learning or not was still a question. 
From the late 1970 s to the early 1980 s, researchers began to realize the important relationship between gender differences and LLSs when learners acquired an L2, but the literature on gender differences in L2 reading performance was relatively scarce (Phakiti, 2003, p.650). Politzer (1983) stated that variance due to the sex of learners did exist with regard to such variables as social interaction. He also showed that females used social learning strategies more than males. Oxford, Nyikos \& Ehrman (1988) published the journal The Role of Styles and Strategies in Second Language Learning. Their study indicated that females had more positive attitudes to a second language compared with males. And females more used learning strategies than males, especially for social strategies.

From the late 1980s to the 1990s, Wenden and Rubin (1987) published Learning Strategies in Language Learning, O'Malley and Chamot (1990) published Learning Strategies in Second Language Acquisition, and Oxford (1990) published Language Learning Strategies: What Every Teacher Should Know. Their masterpieces mainly reflected research achievement on LLSs in the 1980s and also represented research quality at that time. Green \& Oxford (1995) did an experiment at a university and found that female students more used metacognitive, memory, social and affective strategies compared with male students. As for SILL questionnaire, 14 of the 50 items were used more often by female students, but merely one was more often used by male students which is "watching TV programs and video movies in English". Meanwhile, according to the findings of their study, they concluded that it was unsure enough that whether male students or female students were more successful at language learning. Purpura (1997) conducted research on 1382 students from seventeen centers in three European countries. Students were asked to finish an 80-item metacognitive and cognitive strategies questionnaire and a 70-item language test. He found that metacognitive strategies had a significant, positive and direct impact on cognitive strategies; cognitive strategies had no significant influence on grammar or reading ability; the more the students used memory strategies, the worse they performed. Goh \& Kwah (1997) made fully use of Oxford's SILL questionnaire in Singapore to test LLSs with 175 Chinese students. They concluded that female students used all LLSs more frequently than male students.

Phakiti (2006) examined 358 EFL learners and asked them to finish an 85-item reading comprehension achievement test (only multiple choice) followed by a cognitive-metacognitive questionnaire on their performance. The results were that metacognitive and cognitive strategies had a positive relationship with the reading test performance; superior learners showed higher metacognitive strategy use than average learners. Radwan (2011) did research on 128 English major students with SILL questionnaire. One of the results was that female students more used social strategies than male students for they were more superior to build social networks; the other was that higher proficiency levels' language learners more used metacognitive, cognitive and affective strategies. Zhang, Goh and Kunnan (2014) examined 593 Chinese college test takers and asked them to respond to a metacognitive and cognitive strategies questionnaire with 38 items and a reading test with 50 items. They found that test takers' metacognitive strategy use was related to cognitive strategy use for improving their reading test performance; test takers' strategy use had a significant effect on their lexico-grammatical reading ability.

However, some of the studies did not prove that gender affected LLSs. We must admit that this variable is not universal. For instance, Kim (1995) took Korean adults learning English as an example and found that there was no difference between male students and female students in using LLSs. Also, Heuring \& Zhou (1995) adopted SILL questionnaire and did the research in China and pointed out that the frequency of using LLSs between male students and female students was the same. Phakiti (2003) did research on 384 Thai university students. They were asked to take a reading comprehension test (only multiple choice) followed by a questionnaire on strategy use. He found that male students more used metacognitive strategies than female students. However, gender showed no differences in both reading test performance and metacognitive and cognitive strategy use questionnaire.

\section{Research on Gender Differences in LLSs in China}

In China, research on LLSs started from the mid of the 1980s. Huang (1985), Zhuang (1989), Wen (1996) are regarded as the most well-known researchers. To begin with, Huang's (1985) An investigation of learning strategies in oral communication that Chinese EFL learners in China employ marked the beginning of LLSs research on Chinese learners learning an L2. In the late 1980s, researchers in China gradually researched the relationship between gender and LLSs. Zhuang (1989) highlighted that it was believed that males and females were born with different linguistic advantages, such as, females learned to speak earlier than males, and females learned a foreign language faster and better than males. Then, Wen (1996) stated that research related to LLSs indicated that when other variables were almost on equal terms, learning strategies had a decisive impact on grades. In 2003, she wrote Chinese Contemporary English Learning and Learning Strategies Research to ensure her viewpoint.

Rao (2005) used SILL questionnaire to examine 217 Chinese students learning English as their second language. He found that female students more used the overall strategy. Zhuang and Wang (2009) found that female students more used all the LLSs than male students. And they were relatively reserved and cautious but more comprehensive in information processing than male students. Huang (2012) found that male students and female students used different strategies, especially for social strategies, affective strategies, compensatory strategies and social strategies, when they acquired a second language. Liu (2012) examined senior high school students to understand the relationship between gender and LLSs. The result was that female students more used all the LLSs than male students.

Therefore, gender differences did have influence on LLSs. Foreign countries have done much more research on gender differences in LLSs than China. Thus, it is essential to do more research on this topic in China. It is not difficult to find that the purpose of this paper is to investigate the relationship between gender and LLSs. To be more specific, core research questions of this current study are:

Research Question One: Is there a difference in LLSs use by gender?

Research Question Two: What is the relationship between gender and frequency of LLSs use?

\section{Methodology}

Participants

Processing math: $62 \%$ 
Table 7 presents information of participants in the study. A total of 188 ESL students ( $M=92,48.9 \%$; $F=96,51.1 \%$ ) in a Macau public university took part in this research study. All the students are Chinese. Their first language is Chinese Mandarin or Cantonese and their second language is English. They all have at least six years' English learning experience (both three years in middle school and senior high school). In this university, English is designed to teach students listening, speaking, reading and writing skills. Students are taught in English, but they are divided into different levels due to their varied English proficiencies.

Table 7

Participants Information

\begin{tabular}{ll} 
Number & 188 students $(\mathrm{M}=92, \mathrm{~F}=96)$ \\
Age & 17 to 20 years old \\
Nationality & China \\
School & Macau public university \\
First Language & Chinese Mandarin or Cantonese \\
Second Language & English \\
English Learning & At least six years (three years in middle school and three years in senior high school) \\
\hline
\end{tabular}

\section{Instruments}

\section{Questionnaire (Strategy Inventory for Language Leaming, SILL)}

The Strategy Inventory for Language Learning (SILL, version 7.0) designed by Oxford (1990) is a self-rating, paper-and-pencil questionnaire that has been the key instrument in more than 40 studies (Zou, 2007, p.27). The whole questionnaire is composed of 50 items. According to Oxford's classification system, strategies were grouped into six categories: memory strategies (items 1-9), cognitive strategies (items 10-23), compensatory strategies (items 24-29), metacognitive strategies (items 30-38), affective strategies (items 39-44) and social strategies (items 45-50). Students were required to carefully read each statement and circle the option ( $1=$ Never or almost never true of me, $2=$ Usually not true of me, $3=$ Somewhat true of me, $4=$ Usually true of me, $5=$ Always or almost always true of me) that most accurately describes his or her real situation.

I made an online form includes Part A with students' personal information including name, student ID, gender, age, major, nationality, first language, second language and English levels and Part B for responses to the SILL questionnaire. According to the Personal Information Protection Act in Macau, I promised in the online form that these data were only for academic research use and would not be revealed. Also, to avoid misunderstanding, Liao's (2002) Chinese version of the SILL questionnaire was adopted so that the questionnaire was more straightforward for students to understand.

\section{Data Collection}

In this paper, only frequency of high strategy use and low strategy use were taken into consideration. According to Oxford and Burry Stock (1995), 3.5-5.0 reflects the high use of that strategy, 2.5-3.4 means medium use and 1.0-2.4 represents low use. And Table 8 shows the number of students' strategy use within each range. Mean of strategy use for each student was computed via SPSS 22.0. If the mean falls into the range from 3.5 to 5.0 , then the student belongs to high strategy use; if the mean falls into 1.0 to 2.4 , then he or she belongs to low strategy use. Table 8 also displays the number of students' strategy use by gender

\section{Table 8}

Number of High or Low Strategy Use by Gender ( $N=188, M=92, F=96)$

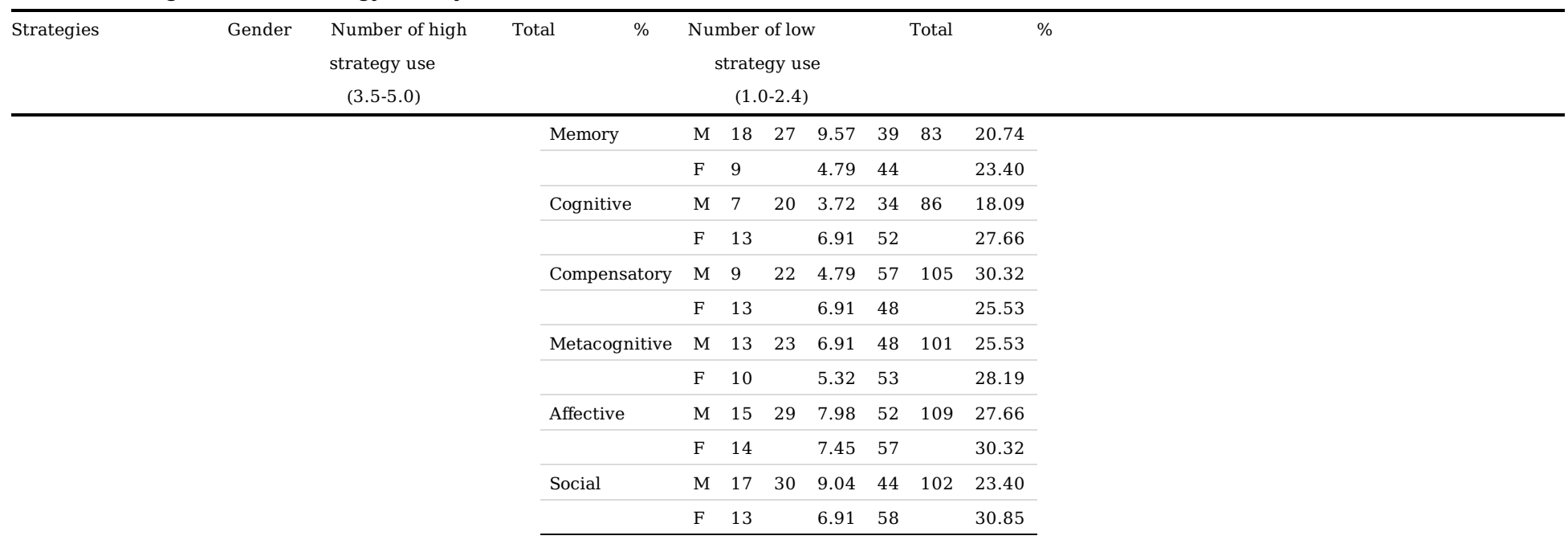

\section{Data Analysis}


Statistical Package for the Social Sciences (SPSS, version 22.0) was used to calculate descriptive statistics such as mean, standard deviation, significance and correlation. T-test was used to examine the relationship between gender and LLSs.

\section{Results And Discussion}

Research Question One: Is there a difference in LLSs use by gender?

\section{Results for Students' SILL Questionnaire}

\section{Overall Strategy Use}

Table 9 shows that the overall mean of the strategy use for all study participants is 3.24. According to Oxford and Burry Stock (1995), 3.5-5.0 reflects the high use of that strategy, 2.5-3.4 means medium use and 1.0-2.4 represents low use. Thus, the mean of strategy use fell into the range from 2.5 to 3.4 which is the medium use. It indicates that students "sometimes" use LLSs.

From Figure 1, it is obvious to see that, among these six strategies, metacognitive strategies were the most frequently used and memory strategies were the least frequently used. And rankings of the other four strategies were cognitive, affective, compensatory and social strategies.

Metacognitive strategies as the highest focus on centering, arranging and planning and evaluating one's learning. According to Shmais (2003), Khalil (2005), Goh \& Kwah (1997), Bremmer (1999) and Liu (2004), they all found that Chinese students or even students from Asia countries put metacognitive strategies at the first place. For one thing, when students have classes in the school, they mainly focus on understanding of language and they are accustomed to knowing what to learn or how to learn. Thus, learning becomes important to study; for another, since English is not their first language, they do not have many chances to practice or speak English all the time. It leads to that it is relatively difficult for them to master an L2. However, students now have much more consciousness of learning a foreign language. With the help of metacognitive strategies, they can make up what they lack.

A very interesting outcome was that memory strategies were the least frequently used among $188 \mathrm{ESL}$ students. This result may show that students spent less time in creating mental linkages, applying images and sounds, reviewing well and employing action. Goh \& Kwah (1997), Lan \& Oxford (2003) and Liu (2004) also found the similar result. Kohn (1992) in his paper once said that Chinese students always memorized words or phrases but ignored to think about meaning or usage of those words or phrases. However, the least frequently used by students did not mean that memory strategies were totally abandoned. It just meant that it was not such high compared with other strategies.

\section{Table 9}

Mean and Standard Deviation of LLSs Indicating Strategy Use $(N=188)$

\begin{tabular}{lcc}
\hline Strategies & 'X & S.D. \\
\hline Memory & 3.06 & 0.78 \\
Cognitive & 3.32 & 0.62 \\
Compensatory & 3.22 & 0.63 \\
Metacognitive & 3.45 & 0.64 \\
Affective & 3.24 & 0.73 \\
Social & 3.16 & 0.58 \\
\hline Overall Total & 3.24 & 0.57 \\
\hline
\end{tabular}

\section{Overall Strategy Use by Gender}

T-test was performed to examine the mean, standard deviation and significance of LLSs indicating strategy use by gender (see Table 10). According to Table 10 , the overall total mean of male students is 3.22 and 3.26 for female students which indicates that gender showed differences on LLSs. It is apparent that male students more used compensatory and affective strategies while female students more used memory, cognitive, metacognitive and social strategies. And the result of significance indicates that there was a statistically significant difference between gender and memory $(p=.03)$, compensatory $(p=.05)$, metacognitive $(p=.02)$ and social $(p=.05)$ strategies. But there was no significant effect on cognitive $(p=.19)$ and affective $(p=.61)$ strategies.

The overall total mean for male students' strategy use is 3.22 which is higher than the mean of memory $(X=3.01)$ and socialstrategies $(X=3.12)$, but lower than the mean of compensatory $(X=3.24)$, mincognitive $(X=3.41)$ and affective strategies (

$X=3.27$ ). Amongthem, ma $\leq$ studentsusedm $\eta$ cognitivestrategiesthemost and mem or ystrategiesthe $\leq *$. Andtheoverall $\rightarrow$ talmeanf or 1 $\mathrm{X}=3.11)$, compensatory $(X=3.20)$ and socialstrategies $(X=3.20)$ but lower than the mean of cognitive $(X=3.35)$ and micognitivestrategies $(X$ =3.49). Among them, female students used metacognitive strategies the most and memory strategies the least.

Table 10

Mean and Standard Deviation of LLSs Indicating Strategy Use by Gender (N=188, M=92, F=96) 


\begin{tabular}{|c|c|c|c|c|}
\hline Strategies & Gender & ‘ $\mathrm{X}$ & S.D. & Sig. \\
\hline \multirow[t]{2}{*}{ Memory } & $\mathrm{M}$ & 3.01 & .48 & $.03 *$ \\
\hline & $\mathrm{F}$ & 3.11 & .53 & \\
\hline \multirow[t]{2}{*}{ Cognitive } & M & 3.29 & .57 & .19 \\
\hline & $\mathrm{F}$ & 3.35 & .57 & \\
\hline \multirow[t]{2}{*}{ Compensatory } & $\mathrm{M}$ & 3.24 & .64 & $.05 *$ \\
\hline & $\mathrm{F}$ & 3.20 & .48 & \\
\hline \multirow[t]{2}{*}{ Metacognitive } & $\mathrm{M}$ & 3.41 & .63 & $.02 *$ \\
\hline & $\mathrm{F}$ & 3.49 & .61 & \\
\hline \multirow[t]{2}{*}{ Affective } & $\mathrm{M}$ & 3.27 & .56 & .61 \\
\hline & $\mathrm{F}$ & 3.21 & .58 & \\
\hline \multirow[t]{2}{*}{ Social } & $\mathrm{M}$ & 3.12 & .49 & $.05 *$ \\
\hline & $\mathrm{F}$ & 3.20 & .67 & \\
\hline \multirow[t]{2}{*}{ Overall Total } & $\mathrm{M}$ & 3.22 & .52 & $.04 *$ \\
\hline & $\mathrm{F}$ & 3.26 & .54 & \\
\hline
\end{tabular}

\section{The Five Most and Least Frequently Used Strategies by Male and Female Students}

Table 11 and Table 12 present the five most and least frequently used strategies by male and female students. Focusing on the five most frequently used strategies by male and female students, it was found that both male and female students highly used "I watch English language TV shows spoken in English or go to movies spoken in English" ( $X=3.77 ; X=4.17)$ which belongs to a cognitive strategy. It is not strange for nowadays people are accustomed to watching various TV shows in their spare time, such as American dramas, Britain dramas, etc. Among students, this kind of situation is much more commonplace. During the process of watching these English TV shows, it is also a good chance for them to learn a foreign language.

Then, Table 13 shows the five most frequently used strategies by male students, and "If I can't think of an English word, I use a word or phrase that means the same thing" (

$X=4.16$ ) ied $\rightarrow$ acompensa $\rightarrow$ rystrategyisatthe $T$ place. Imag $\in$ ewhenyouwant $\rightarrow$ say"Thanksf or giv $\in$ gmethisopp or tunity!" butyouf $\mathrm{c}$ $X=3.89$ ) showing that male students may have the sub-consciousness to concentrate on the one who speaks English. "When I can't think of a word during a conversation in English, I use gestures" ( $X=3.67)$ indicates the importance of body language. And "I encourage myself to speak English even when I am afraid of making a mistake" $(X=3.63)$ may argue that male students are more of self-confidence so that they will encourage themselves when they meet any communication blockages.

\section{Table 11}

Five Most Frequently Used Strategies by Male Students (N=92)

No. Strategy Content 'x Classification

\begin{tabular}{llll}
29 & If I can't think of an English word, I use a word or phrase that means the same thing. & 4.16 & Compensatory \\
\hline 32 & I pay attention when someone is speaking English. & 3.89 & Metacognitive \\
\hline 15 & I watch English language TV shows spoken in English or go to movies spoken in English. & 3.77 & Cognitive \\
\hline 25 & When I can't think of a word during a conversation in English, I use gestures. & 3.67 & Compensatory \\
\hline 40 & I encourage myself to speak English even when I am afraid of making a mistake. & 3.63 & Affective \\
\hline
\end{tabular}

Compared with male students, the five most frequently used strategies by female students seemed to be slightly different (see Table 4-4). "I notice my English mistakes and use that information to help me do better" (X=3.88) at the second place indicating that female students are aware of their mistakes when they learn English. They focus on what they do wrong and then find a solution to do better next time. "I practice the sounds of English" (X=3.82) indicates that female students concentrae more on sounds and pronunciation than male students. Because good accent may win the reputation and respect from native speakers or people who speak English. In contrast to male students, female students are shier when they speak English. Thus, "I try to relax whenever I feel afraid of using English" ( $X=3.69)$ is at such a high place. "To understand unfamiliar English words, I make guesses" (X=3.62) may reflect that female students think more than male students, and sometimes their intuition is more accurate than male students.

\section{Table 12}

Five Most Frequently Used Strategies by Female Students $(N=96)$

No. Strategy Content $\mathrm{X}$

Classification

\begin{tabular}{llrl}
15 & I watch English language TV shows spoken in English or go to movies spoken in English. & 4.17 & Cognitive \\
\hline 31 & I notice my English mistakes and use that information to help me do better. & 3.88 & Metacognitive \\
\hline 12 & I practice the sounds of English. & 3.82 & Cognitive \\
\hline 39 & I try to relax whenever I feel afraid of using English. & 3.69 & Social \\
\hline 24 & To understand unfamiliar English words, I make guesses. & 3.62 & Compensatory \\
\hline
\end{tabular}


As for the five least frequently used strategies by male and female students, "I review English lessons often" ( $X=2.88$; $X=2.58)$ indicates that both male and female students do not like reviewing English during learning. This situation indeed fits the current Chinese L2 learners. I once worked as a teaching assistant (TA) in Shanghai New Oriental School. Students there wanted to pass CET-4 or CET-6 (College English Test Band-4 or Band-6). Every day the teacher asked students to review what they had learned that day, and there would be a dictation for the next day. To our surprise, most of the students got a low mark for that dictation. When I asked some of the students, they responded to me that they did not like reviewing but more liked understanding. Therefore, it is normal that No.8 is the item that both male and female students do not like. Keeping a diary is also rare for students, let alone writing down some feelings. Information technology develops so fast, few people keep a diary every day. That is why "I write down my feelings in a language learning diary" ( $\mathrm{X}=2.29$ ) is in the table.

Table 13 illustrates the five least frequently used strategies by male students. "I use flashcards to remember new English words" (X=2.17) is at the top place. Nowadays people have various kinds of mobile phone applications. Those apps are easy and free to download so that students have more ways to learn English. Making flashcard is useful, but it costs too much energy, time and maybe expense. People are more inclined to use a convenient way. We have to admit that it was popular several years ago, but nowadays not many people take this way. "I ask questions in English" ( $X=2.52)$ is at the third place because since they are all Chinese, it is more convenient for them to interact in their mother tongue. If they want to ask a question, most people prefer to choose an easy way. Sometimes they may think it is troublesome if they ask a question in English but the opposite side does not understand at all. "I try to learn about the culture of English speakers" ( $X=2.88$ ) is also in the table. If one majors in English or history so that he or she has the interest or necessity to understand the culture of western countries. Or students may do not have chances or interests to learn at all.

\section{Table 13}

Five Least Frequently Used Strategies by Male Students $(N=92)$

\begin{tabular}{|c|c|c|c|c|c|}
\hline \multirow[t]{2}{*}{ No. } & \multirow[t]{2}{*}{ Strategy Content } & \multicolumn{2}{|r|}{$\mathrm{X}$} & \multicolumn{2}{|c|}{ Classification } \\
\hline & & 6 & I use flashcards to remember new English words. & 2.17 & Memory \\
\hline & & 43 & I write down my feelings in a language learning diary. & 2.29 & Affective \\
\hline & & 49 & I ask questions in English. & 2.52 & Social \\
\hline & & 50 & I try to learn about the culture of English speakers. & 2.79 & Social \\
\hline & & 8 & I review English lessons often. & 2.88 & Memory \\
\hline
\end{tabular}

The five least frequently used strategies by female students are shown in Table 14. "I physically act out new English words" showed that female students are shy so that sometimes they are afraid of making some actions in the case that they will become a laughing stock. "I start conversations in English" ( $\mathrm{X}=2.92)$ is similar to "I ask questions in English". Because they are all Chinese students, it is a little bit strange for them to start their conversation without their mother tongue. Only both of them want to practice their oral English, or it is so rare to find this circumstance because they can explain themselves clearly in Chinese. Next, since this university is an international university, students here are from all over the world. But when one meets any problem, he or she may find his or her friends for help. Sometimes Chinese students are passive to talk with international students. That is the reason "I ask for help from English speakers" $(X=3.04)$ is in the table.

\section{Table 14}

Five Least Frequently Used Strategies by Female Students $(N=96)$

\begin{tabular}{|c|c|c|c|c|c|}
\hline \multirow[t]{2}{*}{ No. } & \multirow[t]{2}{*}{ Strategy Content } & \multicolumn{2}{|r|}{$` \mathrm{X}$} & \multicolumn{2}{|c|}{ Classification } \\
\hline & & 7 & I physically act out new English words. & 2.14 & Memory \\
\hline & & 43 & I write down my feelings in a language learning diary. & 2.32 & Affective \\
\hline & & 8 & I review English lessons often. & 2.58 & Memory \\
\hline & & 10 & I start conversations in English. & 2.92 & Cognitive \\
\hline & & 48 & I ask for help from English speakers. & 3.04 & Social \\
\hline
\end{tabular}

For the most frequently used strategies, male students are more straightforward so that they may use body language which is a compensatory strategy to convey the meaning of a word they are not able to express in English. While female students are shy so that they hardly ever use the memory strategies to act out new English words. When speaking English, most of the male students use the affective strategies to encourage themselves, while most of the female students use the social strategies to relax. Most of the male students use the metacognitive strategies paying attention to the person who speaks English, but most of the female students use the cognitive strategies laying emphasis on the sounds of English. But female students also use metacognitive strategies to notice the mistakes they have made. When meeting a word, both male students and female students use the compensatory strategies, but most of the male students use a synonym to replace the word that they have forgotten, while most of the female students guess what it means.

For the least frequently used strategies, when speaking English, most of the male students do not use social strategies to ask questions in English, while most of the female students do not use cognitive strategies to start conversations in English. Also, female students may not adopt social strategies to ask help from English speakers as well. And most of the male students do not use memory strategies to make the flashcards.

Above all, it could be concluded that though male and female students had some commons in language learning, e.g., both male and female students like watching English language TV shows; they neither like keeping a diary or reviewing English lessons. Under most of the circumstances, they used different strategies when they acquired a second language.

Processing math: $62 \%$ 
Research Question Two: What is the relationship between gender and frequency of LLSs use?

Results for Gender and Students' SILL Questionnaire Correlation

Correlation refers to the degree of relationship (or dependency) between two variables. Two ways were used to get the correlation in this paper. A total of 188 ESL students $(M=92, F=96)$ in a Macau public university were asked to finish the questionnaire designed by Oxford (1992) and they were divided into high strategy use and low strategy use.

Table 15 directly displays the correlation of high and low LLSs use by each gender as well as gender and frequency of LLSs. For high and low LLSs use, the strongest correlation for male students was affective strategies $(r=.86)$ and the weakest was cognitive strategies ( $r=.41)$. It means male students used very similar ways of learning English via affective strategies both from high and low LLSs use and they used different ways via cognitive strategies. As for female students, both affective $(r=.84)$ and social strategies $(r=.84)$ had the strongest correlation, and the weakest was memory strategies $(r=.61)$. It indicates that female students used very similar ways in learning English via affective and social strategies both from high and low LLSs use and they used different ways via memory strategies.

For gender and frequency of LLSs use, the strongest correlation falls into the gender and metacognitive strategies ( $r=.88)$. This result was consistent with Liu's (2004) study. In other words, male and female students used very similar ways when they learned English via metacognitive strategies. It is maybe because that Chinese EFL learners do not have much opportunity to be exposed to the target language. Thus, they do not have much chance to practice or pick up the target language. The correlation of gender and compensatory strategies is at the second place ( $r=.86)$. Riazi and Rahimi (2005) once said that high use of compensatory strategies usually characterized the learners who struggled with low competence. It also fits that Chinese students do not have much chance to learn a target language. Thus, both male and female students may use compensatory strategies to make up the linguistic deficiencies. The correlation of gender and memory strategies $(r=.64)$ has the weakest correlation. It is an interesting result because teachers in China often encourage students to repeat and recite texts to indicate their understanding. Both male and female students receive this kind of education. Therefore, more and more ways have been created by students to memorize the words, phrases, paragraphs or even passages. They are more inclined to understand the grammar and linguistic rules. This may be the reason that the correlation of gender and memory strategies had the weakest correlation because male and female students have multifarious methods to memorize something. The correlation of gender and social strategies $(r=.66)$ comes to the similar consequence. Because male and female students may have different ways to interact with other people. They gain the target language unknowingly.

Table 15

Correlation of Gender and Frequency of LLSs Use (N=188, M=92, F=96)

\begin{tabular}{|c|c|c|c|c|}
\hline Strategies & Gender & High and Low & LLSs use $r$ & $\begin{array}{l}\text { Gender and frequency of } \\
\text { LLSs use } r\end{array}$ \\
\hline \multirow[t]{2}{*}{ Memory } & $\mathrm{M}$ & .78 & & .64 \\
\hline & $\mathrm{F}$ & .61 & & \\
\hline \multirow[t]{2}{*}{ Cognitive } & $\mathrm{M}$ & .41 & & .78 \\
\hline & $\mathrm{F}$ & .79 & & \\
\hline \multirow[t]{2}{*}{ Compensatory } & $\mathrm{M}$ & .86 & & .86 \\
\hline & $\mathrm{F}$ & .74 & & \\
\hline \multirow[t]{2}{*}{ Metacognitive } & $\mathrm{M}$ & .69 & & .88 \\
\hline & $\mathrm{F}$ & .77 & & \\
\hline \multirow[t]{2}{*}{ Affective } & $\mathrm{M}$ & .86 & & .71 \\
\hline & $\mathrm{F}$ & .84 & & \\
\hline \multirow[t]{2}{*}{ Social } & $\mathrm{M}$ & .82 & & .66 \\
\hline & $\mathrm{F}$ & .84 & & \\
\hline
\end{tabular}

\section{Conclusion}

\section{Major Findings}

For question one, there is a difference in LLSs use by gender. It was found that students used metacognitive strategies the most and memory strategies the least. In terms of gender, female students more used strategies when they learned a foreign language. Also, male students more used compensatory and affective strategies, while female students more used memory, cognitive, metacognitive and social strategies. These findings were similar to Green and Oxford (1995) and Goh and Kwah's (1997) research. Both male and female students used metacognitive strategies the most and memory strategies the least. This finding was slightly different from Radwan's (2011) study as he found that female students used social strategies the most. For question two it was found that gender and metacognitive strategies had the highest correlation which indicates that male and female students used very similar ways when they learned English using metacognitive strategies. Gender and memory strategies had the weakest correlation which indicated that male and female students used relatively different ways of learning English using memory strategies. This result was consistent with Liu's (2004) study but a little bit different from Oxford and Ehrman (1995)'s study. Because in their study, they found that cognitive strategies had the strongest correlation with gender differentiation.

\section{Limitations and Further Directions}

Processing math: $62 \%$

Page $11 / 14$ 
First, it was not enough to use SILL questionnaire for only once because sometimes self-report data are not such reliable. And it was not enough to only use SILL questionnaire to get final results. Second, some of the variables such as aptitude and motivation were not controlled in this study. Finally, the participants included in this paper were selected only at one university in Macau. Thus, the sample may not be representative for the whole Macau context. Different schools may have different results.

To solve the first limitation, it is better to ask this group of students to do the questionnaire for a second time after several days. And then the reliability of their responses for both first and second time should be examined to see whether these data are useful for the further research. Also, it is better to combine the SILL questionnaire with students' test performance. In other words, it is better to ask students to finish a test followed by a strategy use questionnaire related to that test. To solve the second limitation, it is better to take variables like motivation and aptitude into consideration. To make the outcome more accurate, it is better to control some more variables. To solve the last limitation, it is encouraged to select participants from other schools in Macau whenever time and resources are available.

\section{Concluding Remark}

To sum up, this study may bring about some profound contributions to the teaching-learning context and the arena of second language acquisition. For students, they can learn English more efficiently and effectively with the guidance of proper learning strategies. And students with gender differentiation will use more useful strategies when learning a foreign language; For teachers, they can teach students with their actual needs with the help of learning strategies.

\section{List Of Abbreviations}

LLSs: Language learning strategies

LUSs: Language use strategies

SILL: Strategy inventory for language learning

SLA: Second language acquisition

\section{Declarations}

\section{Availability of data and material}

I am sorry that due to the policy of university, the data is not available.

\section{Funding}

There is no funding for this short report.

\section{Competing interests}

The author declares that he has no competing interests.

\section{Author's contributions}

Firstly, the author carried out the study, participated in the sequence alignment and drafted the manuscript. Secondly, the author collected the data and performed the statistical analyses. Finally, the author revised and polished the manuscript and sumbitted it.

\section{Acknowledgements}

First and foremost, I would like to extend my sincere gratitude to Prof. Antony John Kunnan for his useful suggestions, incisive comments and constructive criticism. Moreover, my special thanks go to Prof. Cecilia Guanfang Zhao and Prof. Matthew Patrick Wallace for their scholarly advice and generous help. Any progress that I have made is the result of their profound concern and selfless devotion. Furthermore, I really to want to say thanks to my language assessment seminar research (LASeR) group members from whom I have learnt so much.

\section{References}

Biggs, J. (1989). Approaches to the enhancement of tertiary teaching. Higher Education Research and Development, 8, 7-25.

Bremmer, S. (1999). Language learning strategies and language proficiency: Investigating the relationship in Hong Kong. The Canadian Modern Language Revie, 55, 26-40.

Brown, A. L., Bransford, J. D., Ferrara, R.A. \& Campione, J.C. (1983). Handbook of Child psychology: Cognitive development. Wiley.

Chamot, A. U. (1987). The learning strategies of ESL students. Prentice Hall.

Chen, X., \& Zheng, M. (2002). English learning strategies. Foreign Language Teaching and Research Press.

Processing math: 62\% Language learning: Insights for learners, teachers and researchers. Newbury House. 
Cohen, A. D. (1998). Strategies in learning and using a second language. Longman.

Ellis, R. (1994). The study of second language acquisition. Oxford.

Gardner, R. C. (1985). Social psychology and second language learning. Arnold.

Goh, C. \& Kwah, P.F. (1997). Chinese ESL students' learning strategies: A look at frequency, proficiency and gender. Hong Kong Journal of Applied Linguistics, 2, 39-50.

Heuring, C. \& Zhou R. (1995). Distance learning strategies in China: Using the strategy inventory for language learning to compare distance and classroom learners in China. Hong Kong Polytechnic University: Working Papers in Linguistics, 1, 95-100.

Huang, J. (2012). Sex differentiation research on University non-English Majors' learning strategies. Journal of Hubei TV University, 32, $126-127$.

Kim, Y. M. (1995): The effect of gender and learning context on the use of language learning strategies. English Teaching, 50, 115-129.

Khalil, A. (2005). Assessment of language learning strategies used by Palestinian EFL learners. Foreign Language Annuals, 38, 108-112.

Kohn, James (1992). Literacy strategies for Chinese university learners. Regents Prentice Hall.

Lan, R., \& Oxford, R. L. (2003). Language learning strategy profiles of elementary school students in Taiwan. International Review of Applied Linguistics and Language Teaching, 41, 339-380.

Liao, B. S. (2007). Teaching of English and translation. Xiu Wei Classics.

Liu, D. Y. (2004). EFL proficiency, gender and language learning strategy use among a group of Chinese technological institute English majors. ARECLSEJournals, 1, 19-32.

Liu, M. (2012). Gender and language learning strategy use - In the case of Chinese high school students. Studies in Literature and Language, 5, 90-94.

Naiman, N., Frohlich, M., Stern, H. H. \& Todesco, A., (1996). The good language learner. Multilingual Matters Co. Ltd.

Nunan, David (1999). Second language teaching \& learning. Heinle \& Heinle Publishers.

O’Malley, J. M. \& Chamot, A. U. (1990). Learning strategies in second language acquisition. Cambridge University Press.

Oxford, R. L. \& Burry-Stock. J. A. (1995). Assessing the use of language learning strategies worldwide with the ESL/EFL version of the strategy inventory for language learning (SILL). System, 23, 1-23.

Oxford, R. L. \& Nyikos. M. (1988). Variables affecting choice of language learning strategies by university students. The Modern Language Journal, 73, 292297.

Oxford, R. L. (1989). Use of language learning strategies: A synthesis of studies with implications for strategy training. System, 17, 1-8.

Oxford, R. L. (1990). Language learning strategies: What every teacher should know. Heinle \& Heinle Publishers.

Oxford, R. L. (1992). Second language research on individual differences. Annual review of applied linguistics, 13, $188-200$.

Phakiti, A. (2003). A Closer Look at Gender and Strategy Use in L2 Reading. Language Learning, 53, 649-702.

Phakiti, A. (2006). A closer look at the relationship of cognitive and metacognitive strategies and their relationships to EFL reading test performance. Melbourne Papers in Language Testing, 1, 53-95.

Politzer, R.L. (1983). An exploratory study of self-reported language learning behaviours and their relation to achievement. Studies in Second Language Acquisition, 6, 54-64.

Purpura, J. (1997). An analysis of the relationships between test takers' cognitive and metacognitive strategy use and second language test performance. Language Learning, 42, 289-325.

Radwan, A. A. (2011). Effects of L2 proficiency and gender on choice of language learning strategies by university students majoring in English. Asian EFL Journal, 8, 115-163.

Rao, Z. H. (2005): Gender, academic major and Chinese students: Use of language learning strategies: Social and educational perspectives. The Journal of Asia TEFL,2, 115-138.

Riazi, A. \& Rahimi, M. (2005). Iranian EFL learners' pattern of language learning strategy use. The Journal of Asia TEFL, 2, 34-50.

Richards, J. C. \& John, Platt (1992). Longman dictionary of language teaching and applied linguistics. Longman.

Processing math: 62\% at the "good language learner" can teach us. TESOL Quarterly, 9, 40-51.

Page $13 / 14$ 
Rubin, J. (1987). Learner strategies: Theoretical assumptions, research history and typology. Longman.

Shmais, W.A. (2003). Language learning strategy use in Palestine. TESL-EJ, 7, 1-4.

Stern, H. H. (1983). Fundamental concepts of language teaching. Shanghai Foreign Language Education Press.

Weinstein, C. E. \& Mayer, R. E. (1986). The teaching of learning strategies. Macmillan.

Wenden, A. \& Rubin, J. (1987). Learner strategies in language learning. London Prentice-Hall International.

Wen, Q. F. (1995). Advanced level English language learning in China: The relationship of modifiable learner variables to learning outcomes. Unpublished Ph.D. thesis, Hong Kong University.

Wu, S. (2008). Journal of Shenyang Institute of Engineering (Social sciences). Major Influence on Language Learning Strategies, 4, 86-88.

Xu, Y. J. (2007). Effect of gender and academic major on Chinese students' use of vocabulary learning strategies. M.A. Thesis, Beijing Language University.

Yan, X. N., \& Zha, D. H. (2011). A Study on English learning strategies of freshmen: Based on the investigation of freshmen from Zhejiang Wanli University. M.A. Thesis, Zhejiang Wanli University.

Zafar, Shahila (2012). Individual learner differences and second language acquisition: A review. Journal of Language Teaching and Research, 4, $639-646$.

Zhang, L.M., Goh, C., \& Kunnan, A.J. (2014). Analysis of test takers' metacognitive and cognitive strategy use and EFL reading test performance: A multisample SEM approach, Language Assessment Quarterly, 11, 76-102.

Zhang, W. Y. (2012). A course in English language learning strategies and study skills. Chong Qing University Press.

Zhuang, Y. \& Wang, C. H. (2009). A Comparative study of learning strategies between boy students and girl students in college. Journal of Hubei Radio \& Television University, 3, 205-319.

Zou, L. (2007): Effect of English proficiency and gender on English majors' use of language learning strategies in a Chinese university. M.A. Thesis, Jiangxi Normal University.

\section{Figures}

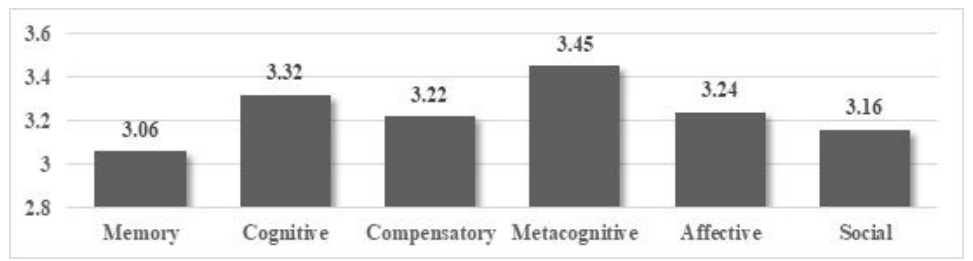

Figure 1

Mean Scores for Strategy Use ( $\mathrm{N}=188)$ 